\title{
O ENSINO DE FÍSICA E SUA INSTRUMENTALIZAÇÃO POR MEIO DOS COMPUTADORES: HISTORICIDADE E PERSPECTIVAS FUTURAS
}

\author{
I. K. O. SILVA, M. J. O. MORAIS II ${ }^{*}$ e D. S. A. FARIA \\ Instituto Federal de Educação, Ciência e Tecnologia do Rio Grande do Norte - Campus Caicó \\ marcal.morais@ifrn.edu.br*
}

Artigo submetido em dezembro/2012 e aceito em fevereiro/2015

DOI: 10.15628/holos.2015.1184

\section{RESUMO}

Este artigo apresenta uma pesquisa de cunho bibliográfico sobre a utilização dos computadores como recurso didático para o ensino de Física. Considerando que a humanidade está em constante transformação, o ensino de Física acompanha essa evolução, à medida que utiliza o computador como recurso didático acessível aos alunos. A relevância desse estudo reside na importância de conhecer o contexto histórico em que o ensino de física se realizou, a concepção atual de ensino de física e a relação professor aluno. O computador instrumentaliza as aulas de Física e atende à exigência atual de formar cidadãos críticos, capazes de pensar, refletir e questionar a realidade em que estão inseridos. Nesse sentido, salientamos no artigo as contribuições que o saber físico promove culturalmente no aluno quando este se faz por meio de uma aprendizagem significativa por meio dos computadores.

PALAVRAS-CHAVE: Ensino de física, Computador, Recurso Didático.

\section{THE TEACHING OF PHYSICS AND ITS INSTRUMENTALIZATION THROUGH THE COMPUTERS: HISTORICITY AND FUTURE PERSPECTIVES}

\begin{abstract}
This article presents bibliographical a survey on the use of computers as an educational resource for the teaching of physics. Considering that humanity is in constant change, teaching physics follows this evolution by using computers as an accessible teaching resource to students. The relevance of this study lies in the importance of knowing the historical context in which the teaching of physics took place, the current conception of physics teaching and the student/teacher
\end{abstract}

relation. The computer works as an instrument in physics classes and provides oportunities for students to become active citizens, enabling them to critically think, reflect and question the reality in which they live. Therefore, the article identified the cultural contributions that physical knowledge promotes in students when it is done via a significant computer learning process.

KEYWORDS: Teaching of Physics, Computer, educational resource. 


\section{INTRODUÇÃO}

Para o exercício da docência em Física, faz-se necessário, à priori, refletir sobre o uso de estratégias didáticas que possibilitem a ação e interação entre docente e discente, o que poderá ser viabilizado por meio da utilização de novos recursos tecnológicos, entre os quais, o computador. Discutir o uso do computador no ensino de Física contribuirá para o desenvolvimento de práticas que possibilitarão um ensino mais significativo e criativo. Embora alguns ainda considerem o professor como detentor absoluto do conhecimento e centro do processo de ensino e aprendizagem, outros concordam que uma aprendizagem significativa requer o envolvimento de professores e alunos enquanto parceiros na busca pelo conhecimento. Nessa perspectiva, Freire (1996) afirma que:

[...] não há docência sem discência, as duas se explicam, e seus sujeitos, apesar das diferenças que os conotam, não se reduzem à condição de objeto, um do outro. Quem ensina aprende ao ensinar, e quem aprende ensina ao aprender (FREIRE, 1996, p.25).

Fundamentado em Freire (1996), inferimos que o ensino de Física exige a formação de cidadãos críticos, capazes de questionar a realidade, de resolver problemas, de desenvolver o raciocínio lógico, a criatividade e a capacidade de análise crítica, selecionando procedimentos e verificando sua adequação na vivência diária dos estudantes.

Ao investigar estas questões, verificamos a inserção do uso do computador no ensino de Física. Tal proposta acaba implicando em mudanças significativas para o trabalho dos docentes, haja vista que precisam atender às demandas advindas das novas tecnologias, precisando se capacitar profissionalmente para acompanhá-las.

Neste sentido, o presente trabalho apresenta-se estruturado em quatro partes; a primeira parte analisa a historicidade do ensino de física no Brasil. A segunda parte apresenta um relato da aplicação do computador no ensino de física, a terceira discute a relação entre professoraluno e os recursos utilizados atualmente e, na última e quarta parte, discute-se as perspectivas futuras para o ensino de Física. Ao final, serão feitas as considerações finais.

\section{O ENSINO DE FÍSICA NO BRASIL: A HISTORICIDADE ATRAVÉS DAS AÇÕES}

A educação é um processo de partilha de saberes entre docentes e discentes. No âmbito do ensino de Física, o processo educacional parte da curiosidade de se compreender os fenômenos físicos. Essa curiosidade se inicia nas brincadeiras de criança e se conclui na escola, local onde o ensino deve estimular motivar e propiciar aprendizagens significativas para a vida dos alunos, devendo romper com as formas tradicionais de ensinar física, com vistas à superação da representação dessa disciplina como difícil e complexa. Concebida enquanto ciências, o ensino de Física no Brasil inicia-se desde a Colônia, sendo este desenvolvido pelos jesuítas.

$\mathrm{Na}$ fase do Brasil Império, do ensino secundário até o superior, apenas $20 \%$ da carga horária era destinada para o ensino de ciências. Nessa mesma fase, o ensino continuava clássico e sem preocupações com a cientificidade das ciências. Ainda sobre esta época, Haidar (1972) explicita: 
[...] a ciência é toda observação, toda exatidão, toda verificação experimental. Perceber fenômenos, discernir relações, comparar as analogias e dessemelhanças, classificar as realidades e induzir as leis, eis a ciência, eis, portanto o alvo que a educação deve ter em mira. Ora, os nossos métodos e os nossos programas tendem precisamente ao contrário (...). Em vez de educar no estudante os sentidos, de incentivá-lo a pensar, a escola e o liceu entre nós ocupam-se exclusivamente em criar e desenvolver nele os hábitos mecânicos de decorar e repetir. A ciência e o sopro científico não passam por nós (HAIDAR, 1972).

Conforme citado anteriormente, o ensino de Física no Brasil Império mostrou-se teórico, tradicional e repetitivo, centrado na veiculação do ensino de conceitos científicos e de conhecimentos dissociados da experimentação.

No século XX, já no Brasil República, a carga horária para o ensino desta disciplina sofre aumento, cerca de $27,3 \%$, passando para $33,3 \%$ após a revolução de 1930 . Dessa forma, podemos notar que a evolução nesta área de ensino aconteceu de maneira gradativa e imperceptível até o Brasil República (PILETTI, 1989).

Em junho de 1943, no Brasil, foi criada a primeira instituição destinada para o ensino de ciências, o Instituto Brasileiro de Educação, Ciência e Cultura - IBECC, que visava melhorar a formação científica dos alunos, para que ao ingressarem no ensino superior obtivessem um desempenho satisfatório. Dentre as principais atividades realizadas nesta instituição estão a construção de material para laboratórios, livros didáticos e paradidáticos.

No ano de 1950, com o avanço da industrialização, o ensino de Física passou a fazer parte do currículo do ensino secundário, hoje denominado ensino médio. Ainda, neste mesmo ano, criou-se a IBECC-UNESCO Seção de São Paulo, para discutir os problemas e possíveis soluções para o ensino de Física no Brasil, uma vez que este se encontrava deficiente. A equipe responsável pelo IBECC-UNESCO - Instituto Brasileiro de Educação, Ciência e Cultura e Organização das Nações Unidas para a Educação, Ciência e Cultura trouxe para o Brasil o curso do PSSC - Physical Science Study Committee por estar convencida de sua excelência, após um acompanhamento minucioso de sua evolução nos EUA - Estados Unidos da América. Para a implantação do PSSC no Brasil, contribuíram financeiramente a Fundação Ford e Fundação Rockefeller, com a colaboração da National Science Foundation e Pan American Union. Logo após o PSSC, surgiram outros projetos curriculares. Contudo, nenhum desses projetos obteve sucesso, pois eram claros em dizer como se devia ensinar Física, seja com experimentos, demonstrações, história da ciência e outros instrumentos didáticos, no entanto, não relacionavam o ensino de Física com a sua aprendizagem (MOREIRA, 2000).

A partir da década de 1980 o ensino de Física foi obtendo reconhecimento e importância comprovada para a formação dos alunos, pois a partir do momento em que o aluno começa a entender e a conhecer os fenômenos físicos, eles passam a compreender os diversos fenômenos e situações que ocorrem no seu cotidiano.

Segundo Piletti (1989), percebe-se que, gradativamente, foi ocorrendo um reconhecimento acerca da importância dessa área no currículo do ensino secundário. Um dos fatores que propiciaram este reconhecimento foram as descobertas científicas e inovações tecnológicas realizadas constantemente, as quais permitiram a conclusão de que, um dos meios 
de fazer os alunos participarem desta evolução é elevar o nível médio de cultura científica e tecnológica dos mesmos, tendo em vista que o desenvolvimento da cultura científica de uma sociedade só é possível a partir da contribuição que o ensino de ciências e tecnologia oferece nas escolas. Deste modo o ensino não só de Física, mas de todas as ciências possui um valor intrínseco na formação dos discentes (SASSON et al., 2003).

Contudo, apesar de tantas inovações tecnológicas e descobertas científicas, percebemos, no ensino de ciências, especialmente no ensino de Física, dificuldades para viabilizar mecanismos para operacionalização de um conjunto de atividades contextualizadas que atendam à perspectiva de integrar o aluno à sociedade. Um dos fatores que contribuem para a não integração por parte dos alunos é a forma como os conteúdos são ministrados, pois na maioria das vezes os alunos se deparam com teorias que não se interligam com a sua realidade, tornando as aulas monótonas e abstratas. Outros fatores preocupantes dizem respeito à falta de capacitação dos professores, a ausência de uma infraestrutura adequada para o ensino de Física e o desinteresse na busca por novos recursos metodológicos que facilitem a obtenção dos novos conhecimentos a serem adquiridos. Tradicionalmente, as aulas têm sido desenvolvidas muito mais a partir da própria disciplina do que das experiências dos alunos (PÉREZ GÓMES, 1998).

No contexto educacional brasileiro, a disciplina de Física é lecionada desde o último ano do ensino fundamental, sendo esta uma espécie de adiantamento dos conceitos a serem estudados no ensino médio.

Ao ingressarem no ensino médio os alunos se defrontam com aulas puramente teóricas, tradicionais e de baixa qualidade que são guiadas apenas por livros didáticos que enfatizam os programas de vestibular (BEZERRA et al., 2009).

Segundo Mees (2005), as aulas de física não estão sendo atraentes o suficiente para manter a atenção do aluno e levar a uma conjugação de interesses, onde se possa crescer no conhecimento em Física. Desta forma, cabe ao professor encontrar soluções que tornem suas aulas mais atraentes e motivadoras apresentando os conteúdos de forma dinâmica, estimuladora, organizada e atualizada, mudando sempre seus enfoques e fazendo com que seus alunos associem os conteúdos vistos em sala de aula com o seu cotidiano.

\section{A IMPORTÂNCIA DOS COMPUTADORES ENQUANTO INSTRUMENTOS ACESSÍVEIS PARA O CONHECIMENTO}

Desde a antiguidade, vem sendo pesquisado formas variadas para tornar o processo de ensino e aprendizagem mais satisfatório, tanto para os alunos quanto para os professores. $\mathrm{Na}$ busca por essas formas variadas surgem os computadores, que, inicialmente, aparecem como máquinas que tem como principal objetivo transformar dados em informações. Essas máquinas transcenderam os objetivos principais conquistando um enorme espaço em bancos, empresas, indústrias dentre outros, e, hoje, adentram nas escolas para melhorar e colaborar com uma educação de qualidade.

Assim, o computador é visto como uma ferramenta indispensável no nosso cotidiano e nas escolas, sua utilização vem demonstrando uma maneira lúdica, divertida e prazerosa de se assistir ou conduzir uma aula. 
Nas salas de aula, o computador é um dos poderosos recursos didáticos no processo da construção do conhecimento, pois através destas máquinas os alunos exploram os ambientes virtuais, realizando experiências de investigação e construindo ambientes cognitivos, que permitem desenvolver e organizar suas próprias conclusões sobre determinado conteúdo.

[...] os computadores estão propiciando uma verdadeira revolução no processo ensino-aprendizagem. Uma razão mais óbvia advém dos diferentes tipos de abordagens de ensino que podem ser realizados através do computador, devido aos inúmeros programas desenvolvidos para auxiliar o processo ensinoaprendizagem. Entretanto, a maior contribuição do computador como meio educacional advém do fato do seu uso ter provocado o questionamento dos métodos e processos de ensino utilizados (VALENTE, 1998).

Como mencionado anteriormente, através da utilização dos computadores os professores poderão usufruir de inúmeros recursos midiáticos que são oferecidos por estes, tornando suas aulas mais dinâmicas e atraentes para o alunado.

A utilização de softwares auxilia a aprendizagem dos alunos, colaborando para o seu desenvolvimento e motivando-o a experimentar situações que não são permitidas na realidade (SILVA e MORAIS II, 2011).

Segundo Jonasson (1994), "os aprendizes constroem sua própria realidade ou interpretam-na baseado nas suas percepções das experiências e, portanto, o conhecimento individual é função das experiências tidas, das estruturas mentais e das crenças que são utilizadas para interpretar as coisas". Ao utilizar computadores nas suas salas de aula os professores podem auxiliar seus alunos usando softwares que melhor se adequem as suas capacidades pessoais, superando as deficiências e desenvolvendo competências cognitivas satisfatórias para o processo de ensino e aprendizagem. Além disso, os alunos estão livres para interpretar os problemas propostos pelo professor, analisando os fenômenos físicos envolvidos em determinadas situações e criando seus próprios conceitos.

Entretanto, para que o computador possa ser inserido nas salas de aula e participar do processo de ensino e aprendizagem com êxito é necessário alguns cuidados, tais como: um planejamento prévio da aula a ser ministrada e uma boa qualificação para o corpo docente para que este manipule com autonomia os recursos disponíveis; sendo esta qualificação realizada periodicamente para que assim os professores fiquem sempre atualizados.

Dessa forma, a melhoria no planejamento das aulas e uma boa qualificação docente aumentará significativamente a aprendizagem dos alunos, ocasionando um ganho cognitivo satisfatório.

\section{O COMPUTADOR: UMA RELAÇÃO CONSTRUTIVA DE APRENDIZAGEM ENTRE ALUNO E PROFESSOR}

Vivemos em um mundo cada vez mais voltado para a tecnologia, a qual atua nas mais diversas áreas, desde a criação do celular à utilização do computador enquanto um recurso lúdico, divertido e prazeroso na condução de uma aula. O computador facilita a aprendizagem dos conteúdos e favorece o desenvolvimento cognitivo do aluno, criando estratégias para a solução dos problemas propostos pelo professor. 
Ao utilizar os computadores nas aulas de Física, o professor tem como objetivo facilitar o entendimento dos fenômenos estudados, estimular o aluno cognitivamente e favorecer a construção do conhecimento pelos próprios alunos. De acordo com Souza (2003):

[...] as questões das novas tecnologias e conceitos como saber flexível, aprendizagem cooperativa, interdisciplinaridade, transdisciplinaridade, currículo integrado, redes de aprendizagem e educação continuada e à distância começam a se fazer cada vez mais presentes nos ambientes acadêmicos e políticos, sobretudo quando está em pauta a discussão sobre a necessidade de renovação dos processos educacionais (SOUZA, 2003).

Segundo Fiolhais e Trindade (2003) e Rosa (1995), a potencialização da utilização de computadores nas salas de aula pode acontecer, sob vários enfoques, conforme a tabela abaixo:

Tabela 1: Potencialidades da utilização dos computadores no ensino de Física

\begin{tabular}{|c|c|}
\hline $\begin{array}{l}\text { Potencialidade dos computadores } \\
\text { no ensino de Física }\end{array}$ & Aplicabilidade \\
\hline $\begin{array}{l}\text { Coleta e análise de dados em tempo } \\
\text { real }\end{array}$ & $\begin{array}{l}\text { O aluno apenas interpreta resultados e pode dedicar mais } \\
\text { tempo para analisá-los e interpretá-los, visando compreender o } \\
\text { conteúdo. }\end{array}$ \\
\hline Simulação de fenômenos físicos & $\begin{array}{l}\text { A simulação pode ser estática ou dinâmica. Na simulação } \\
\text { estática o modelo do fenômeno já está pronto e o aluno apenas } \\
\text { manipula os parâmetros e observa o que acontece, enquanto } \\
\text { na simulação dinâmica o aluno elabora um modelo explicativo } \\
\text { do fenômeno. }\end{array}$ \\
\hline Instrução assistida por computador & $\begin{array}{l}\text { Nesta modalidade, o computador funciona como um tutor } \\
\text { mais ou menos rígido dirigindo o estudo do aluno. }\end{array}$ \\
\hline $\begin{array}{l}\text { Utilização para estudo das } \\
\text { habilidades cognitivas do aluno }\end{array}$ & $\begin{array}{l}\text { Neste tipo de utilização o aluno tem uma grande interação } \\
\text { com o computador, pois é ele quem comanda o computador. }\end{array}$ \\
\hline Hipermídia & $\begin{array}{l}\text { Baseia-se no contexto de hipertexto. O termo significa que } \\
\text { um programa pode incluir vários elementos como textos, sons, } \\
\text { imagens (estáticas ou animadas), simulações e vídeo e, uma vez } \\
\text { que há muitos links, é possível ao aluno selecionar as partes } \\
\text { que lhe interessam. }\end{array}$ \\
\hline Realidade Virtual & $\begin{array}{l}\text { As principais características dessa modalidade são a } \\
\text { imersão, a interatividade e a manipulação decorrentes das } \\
\text { ações do usuário tal como no mundo real. }\end{array}$ \\
\hline Internet & $\begin{array}{l}\text { A internet relaciona-se com vários outros meios já } \\
\text { discutidos como: simulações que podem ser utilizadas online } \\
\text { ou carregadas no computador; multimídia e linguagem html, } \\
\text { que é utilizada para criar páginas na internet; realidade virtual } \\
\text { que representa objetos ou cenários tridimensionais, sendo a } \\
\text { modalidade de uso do computador mais interativa e pessoal. }\end{array}$ \\
\hline
\end{tabular}

\section{PERSPECTIVAS FUTURAS PARA O ENSINO DE FÍSICA UTILIZANDO COMPUTADORES}

Existem diversas formas de inserir os computadores no ensino de Física, utilizando estas, para uma compreensão satisfatória dos temas abordados em sala de aula. Desta forma, com sua inserção nas salas de aula, os professores propiciarão aos alunos uma interação maior com a máquina, trocando experiências e levantando hipóteses para a resolução das atividades, facilitando assim o atendimento às habilidades e competências propostas pelos Parâmetros 
Curriculares Nacionais para o Ensino Médio (PCNEM - BRASIL, 1999), proporcionando também a liberdade de intervenção no espaço de aprendizagem (MEDEIROS e MEDEIROS, 2002, p.84).

Dentre as principais potencialidades que envolvem os recursos computacionais, segundo Elias et al (2009) e Fiolhais e Trindade (2003), estão:

- Simulação ou modelagem: A utilização desta modalidade oferece aos alunos uma visualização mais ampla e clara dos conteúdos estudados, gerando motivação na medida em que passam a interagir mais intensamente buscando construir modelos no computador, tendo a disposição um sistema de feedback rápido sobre o que realizaram;

- Coleta e análise de dados em tempo real: Sendo esta considerada bastante útil, pois possibilita a coleta de dados e elaboração de gráficos permitindo que o aluno tenha mais tempo na etapa de análise e interpretação, podendo se concentrar no entendimento do fenômeno estudado sem precisar elaborar tabelas e gráficos, enriquecendo e ampliando as possibilidades de uso dos laboratórios, contribuindo com a experimentação no ensino de Física;

- Edição de filmes e animações: Permite que o aluno visualize o tema estudado em sala de aula, facilitando desse modo a sua aprendizagem;

- Estudo das habilidades cognitivas: O computador possui uma vasta biblioteca de comandos, permitindo aos alunos se concentrarem nos conceitos abordados e, assim, desenvolverem capacidade de abstração, propiciando também o trabalho em equipe;

- Instrução assistida: Sendo esta útil para a apresentação de conteúdo e resolução de problemas, pode não propiciar mudança na prática pedagógica caso o aluno não participe ativamente do processo e o conteúdo seja apresentado como pronto e acabado;

- Multimídia: É uma ferramenta para fácil apresentação dos conteúdos uma vez que se podem apresentar noções sobre as mudanças ocorridas na transição da física clássica para a moderna, além de expor os mais variados conteúdos de forma que a aluno navegue mais facilmente pelos que mais lhe interessar no momento do seu estudo;

- Realidade virtual: Facilita a interação entre o homem e a máquina e o ambiente virtual um cenário constituído por modelos tridimensionais, armazenado e gerido por computador, usando técnicas de computação gráfica;

- Internet: O professor ajudará o aluno a procurar e selecionar a informação mais relevante nos vastos "oceanos de informação" fornecendo-lhe objetivos para neles navegar.

\section{CONSIDERAÇÕES FINAIS}

Nas últimas décadas a utilização de novas tecnologias, como o computador, vem adentrando na educação com o propósito de melhorar o processo de ensino e aprendizagem, auxiliando os alunos na absorção de conteúdos de difícil compreensão. No ensino de Física, a inserção dos computadores atende a necessidade dos professores e do alunado em diversificar os métodos de ensino. 
Deste modo, a aplicabilidade dos computadores nas salas de aula influencia positivamente no processo de ensino e aprendizagem, motivando e tornando a aprendizagem mais significativa para os alunos, que começam a participar ativamente das aulas transformandose de sujeitos passivos a sujeitos ativos, interagindo com o conteúdo e criando estratégias para a solução dos problemas propostos pelo professor. Portanto, faz-se necessário que os professores entendam como integrar o computador nas salas de aula, superando barreiras e possibilitando a transição de um sistema fracionado para um sistema integrado de conteúdos voltados para a resolução de problemas específicos do interesse de cada aluno.

Assim, podemos notar que os computadores têm contribuído para a educação, diversificando os recursos de ensino e criando condições de aprendizagem, que fazem com que o professor deixe de ser o detentor do conhecimento e passe a ser o criador de ambientes de aprendizagem que facilitam o processo de desenvolvimento intelectual do aluno.

\section{AGRADECIMENTOS}

Agradecemos ao CNPQ pelo apoio financeiro dado durante o desenvolvimento desta pesquisa.

\section{REFERÊNCIAS BIBLIOGRÁFICAS}

1. BEZERRA, D. P; GOMES, E. C. S.; MELO, E.S.N.; SOUZA, T.C. A evolução do ensino da Física: perspectiva docente, Scientia Plena, v. 5, n. 9, 2009.

2. BRASIL. Ministério da Educação. Secretaria de Educação Média e Tecnológica. Parâmetros curriculares nacionais: ensino médio. Brasília: MEC, 1999.

3. ELIAS, D. C. N.; AMARAL, L. H.; DE ARAÚJO, M. S. T.; JÚNIOR, C. F. de A. Características e Tendências das Propostas de Utilização das Ferramentas Computacionais no Ensino de Física. In: XVIII Simpósio Nacional de Ensino de Física - XVIII SNEF, 2009, Vitória - ES. Anais do XVIII SNEF, 2009.

4. FIOLHAIS, C., TRINDADE, J. Física no computador: O computador como ferramenta no ensino e na Aprendizagem das Ciências Físicas. Rev. Bras. do Ensino de Física, v. 25, n. 3, p. 259-272, 2003.

5. FREIRE, Paulo. Pedagogia da autonomia: saberes necessários para a prática educativa. São Paulo: Paz e Terra, 1996.

6. HAIDAR, M. de L. M. O ensino secundário no Império brasileiro. São Paulo: Grijalbo/Edusp, 1972.

7. JONASSON, D. Thinking technology: toward a constructivist design model. Educational Technology, v. 34, n. 4, p. 34-37, 1994.

8. MEDEIROS, A., MEDEIROS, C. F. Possibilidades e Limitações das Simulações Computacionais no Ensino de Física. Rev. Bras. do Ensino de Física, v. 24, n. 2, p. 77-86, 2002.

9. MEES, A.A. Implicações das teorias de aprendizagem para o ensino de física. 2005. Disponível em: <http://www.if.ufrgs.br/cref/amees/teorias.htm>, Acessado em: 12 de Junho de 2012. 
10. MOREIRA, A. M; Ensino de Física no Brasil: Retrospectiva e Perspectivas. Rev. Bras. do Ensino de Física, v. 22, n. 1, p. 94-99, 2000.

11. PÉREZ GÓMES, A.I. A aprendizagem escolar: da didática operatória à reconstrução da cultura na sala de aula. Porto Alegre, RS: Artmed, p. 53-65, 1998.

12. PILETTI, Nelson. História da educação no Brasil. São Paulo: Ática, 1989.

13. ROSA, P. R. S. O uso de computadores no Ensino de Física. Rev. Bras. do Ensino de Física, v. 17, n. 2, p. 182-195, 1995.

14. SASSON, A.; VILCheS, A.; De CARVAlHo, A. M. P.; MACEDO, B.; PÉREZ, D. G. Cultura Científica: Um direito de todos. Brasília. UNESCO. 2003

15. SILVA, I. K. de O.; MORAIS II, M. J. de O. Desenvolvimento de Jogos Educacionais no Apoio do Processo de Ensino-Aprendizagem no Ensino Fundamental. Revista Holos, Natal, V. 5, p. 153164, 2011.

16. SOUZA, C. H. M. de. Comunicação, Educação e Novas Tecnologias. Campos dos Goytacazes, RJ: FAFIC, 128p, 2003.

17. VALENTE, J.A. Diferentes usos do computador na Educação. In: VALENTE J. A. (Org.). Computadores e conhecimento: repensando a educação. 2ạ ed. campinas: Gráfica Central UNICAMP, 1998, v., p. 1-27. 